\title{
Serbest Form Yüzeye Sahip Parçaların Üretim Nedenli Hata Miktarlarının Robot Kol Yardımlı Lazer Sensör ile Tespiti
}

\author{
Abdulkadir Çebi ${ }^{1 *}$, Muhammed Turan Aslan ${ }^{2}$, Hasan Demirtaş ${ }^{3}$ \\ ${ }^{1 *}$ Samsun Üniversitesi, Mühendislik Fakültesi, Makine Mühendisliği Bölümü, Samsun, Türkiye, (ORCID ID 0000-0002-3074- \\ 6554), abdulkadir.cebi@samsun.edu.tr \\ ${ }^{2}$ Samsun Üniversitesi, Mühendislik Fakültesi, Makine Mühendisliği Bölümü, Samsun, Türkiye, (ORCID ID 0000-0002-9713- \\ 4763), muhammedturan.aslan@samsun.edu.tr \\ ${ }^{3}$ Samsun Üniversitesi, Mühendislik Fakültesi, Makine Mühendisliği Bölümü, Samsun, Türkiye, (ORCID ID 0000-0001-6067- \\ 9674), hasan.demirtas@samsun.edu.tr
}

(1st International Conference on Applied Engineering and Natural Sciences ICAENS 2021, November 1-3, 2021)

(DOI: $10.31590 /$ ejosat.1013033)

ATIF/REFERENCE: Çebi, A., Aslan, M. T. \& Demirtaş, H. (2021). Serbest Form Yüzeye Sahip Parçaların Üretim Nedenli Hata Miktarlarının Robot Kol Yardımlı Lazer Sensör ile Tespiti. Avrupa Bilim ve Teknoloji Dergisi, (28), 1126-1132

$\ddot{O} z$

3 boyutlu parçaların imalatında, hata miktarlarının tespiti için köprü tip CMM, gantry tip CMM ve yatay kollu CMM gibi yöntem kullanılmaktadır. Endüstride kullanılan koordinat ölçüm cihazları yüksek hassasiyete sahip olmalarına rağmen yüksek fiyat ve düşük hız gibi dezavantajlara sahiptir. Bu çalışmada endüstride kullanılan ölçüm yöntemlerine alternatif oluşturmak amaçlanmaktadır. Serbest form yüzeye sahip metal parçaların imalatı sırasında gerçekleşen hata miktarları, robot kol üzerinde bulunan lazer sensör ile noktasal tespit edilmiştir. Ölçümler için robot kolun hareket şekli, lazer sensörün ölçüm aldığı nokta sayısı ve lazer sensörün iş parçasına olan referans uzaklığı olmak üzere 3 farklı değişken kullanılmıştır. Değişkenlere ait veriler RobotStudio ortamına aktarılmış, deneyler simülasyon motorunda incelenmiş ve deneylere ait RAPID kodları elde edilmiştir. Yüksek hassasiyete sahip lazer sensör ile 27 deney şartı için noktasal tespit yapılmıştır. Deneylerden elde edilen sonuçlar numunenin CAD modeli ile karşılaştırılıp, üretimde gerçekleşen hata miktarı mikrometre $(\mu \mathrm{m})$ olarak tespit edilmiştir. Tespit edilen hata miktarları ise CMM cihazından alınan hata miktarları ile kıyaslanmıştır. Elde edilen sonuçlar MATLAB ortamında oluşturulan grafiklerle incelenmiştir. Nokta sayısının en az olduğu durumlarda standart sapmanın 54,51 ile 74,38 arasında değiştiği ve ölçümün daha homojen bir şekilde dağıldığı görülmüştür. Ortalama hata miktarının ise artan nokta sayısı ile doğru orantılı olduğu tespit edilmiştir. Bu çalışmada alternatif olarak sunulan yöntemin iyileştirilmesi durumunda, serbest form yüzeye sahip metaller için CMM cihazları yerine kullanılabilirliğini göstermektedir.

Anahtar Kelimeler: Lazer sensör, robot kol, serbest form yüzey, kalite kontrol.

\section{Detection of Production Caused Errors of Freeform Surfaces with Robotic Arm Supported Laser Sensor}

\begin{abstract}
In the manufacture of 3 dimensional parts, a method such as bridge type CMM, gantry type CMM and horizontal arm CMM is used to detect errors. The coordinate measuring machines used in the industry have high accuracy but have disadvantages such as high price and low speed. In this study, it is aimed to create an alternative to the measurement methods used in the industry. The errors that occur during the production of freeform surfaces metal parts are determined point by the laser sensor attached to the end of the robot arms. Three different variables are used for the measurements: the path of the robot arm, the number of points, and the reference distance of the laser sensor to the workpiece. Data from variables has been transferred to RobotStudio, experiments are simulated, and RAPID codes are obtained. The high-precision laser sensor is used to point-detect 27 experiment conditions. The results from the experiment conditions are compared to the CAD model of the workpiece and the errors in production are determined as micrometers ( $\mu \mathrm{m})$. The results are analyzed by graphs in MATLAB. It is observed that the.
\end{abstract}

Keywords: Laser sensor, robot arm, freeform surface, quality control. 


\section{Giriş}

İmalat endüstrisinde; üretilen iş parçalarının boyutsal olarak tasarıma olan uygunluklarının kontrol edilmesi, imalat sonrası sürecin önemli bir kısmını oluşturmaktadır (Germani, Mandorli, Mengoni ve Raffaeli, 2010; Huang \& Qian, 2007; Hwang, Tsai \& Chang, 2004; Kruth, Van Gestel, Bleys \& Welkenhuyzen, 2009; Li \& Gu, 2004; Lee, Mou \& Shen, 1997; Lee \& Park, 2000; Martins, Garcia Bermeio, Casanova \& Gonzalez, 2005). CMM cihazları endüstride iş parçalarının boyutsal kontrolü için standart bir araç haline gelmiştir. Parçaların boyutsal kontrolünde geometrinin karmaşıklığı ve hassasiyet ile ilgili beklentiler arttıkça, gelişmiş ölçümler elde etmek için farklı sensörleri birleştiren çok sensörlü cihazlar kullanılmaktadır (Weckenmann, 2009). Özellikle lazer tarayıcılar ile temasa dayalı ölçüm uçlarının birbirlerini tamamlayıcı olmalarından dolayı (Nashman, Yoshimi, Hong \& Rippey, 1997), birlikte kullanılmaları oldukça yaygındır (Huang \& Qian, 2007; Bradley \& Chan, 2001; Carbone, Carocci, Savio ve Sansoni, 2001; Shen, Huang \& Menq, 2001). Birden fazla sensörün kullanıldığı CMM cihazları, karmaşık geometrilerin koordinatlarının yüksek doğrulukta tespiti için kullanışlıdır. Ancak, bu ölçüm sisteminde farklı sensör türlerinin sisteme entegre edilmesi için planlı bir yönteme ihtiyaç duyulmaktadır. Zhao vd. (2012) yaptıkları çalışmada temaslı ölçüm ucu ile bir lazer tarayıcıyı birleştirerek CMM denetimi için otomatik olarak denetim planları oluşturabilen bir metodoloji sunmuşlardır. Temas ile gerçekleşen boyutsal denetime yönelik uygulamalar, çelik gibi sert malzemeler ile yapılmış parçalar ile sınırlı olmasından dolayı Cheng \& Menq (1995) lazer sensör ve CMM cihazını birleştirerek yumuşak malzemelerden yapılmış nesnelerin 3B koordinatını hesaplayan bir sistem geliştirmişlerdir. Yapılan çalışmalara benzer olarak, özellikle üretim hattında karmaşık geometriye sahip parçaların CAD modellerinin mevcut olmaması durumunda tersine mühendisliğe ihtiyaç duyulmaktadır. $\mathrm{Bu}$ amaçla yapılan çalışmalar incelendiğinde Deng, Shark, Matuszewski, Smith \& Cavaccini (2004) yaptıkları çalışmada, havacılık endüstrisinde kullanılan karmaşık geometrik şekillere ve kavisli yüzeylere sahip yapıların CAD modellerinden alınan bilgiler doğrultusunda yüzey kusurlarının $3 \mathrm{~B}$ görselleştirebilen bir yazılım paketi sunmuşlardır. 3B temassız ölçüm sistemlerinde düşük hata toleransı beklenmektedir. $\mathrm{Bu}$ nedenle yüksek hassasiyetli hareket ve konumlandırılma kabiliyetlerine sahip endüstriyel robotlar, 3B temassız ölçüm sistemlerinde siklikla kullanılmaktadır (Morozov, Pierce, MacLeod, Mineo \& Summan, 2018; Heeshin, 2016; Hatwig, Reinhart \& Zaeh, 2010; Idrobo-Pizo, Motta \& Sampaio, 2019; Niola, Rossi, Sergio \& Salvatore, 2010; Ren, Yin \& Zhu, 2012; Li vd. 2011; Tzafestas, Raptis \& Pantazopoulos, 1996; Hatwig, Minnerup, Zaeh \& Reinhard, 2012; Shirinzadeh vd. 2010). Yapılan çalışmalar incelendiğinde; konfokal lazer taramalı sensör, 6 eksenli robot kolun üzerine monte edilerek düz yüzeyli numunelerdeki yüzey pürüzlülük miktarı ölçülmüştür (Fu vd., 2018). Shen \& Zhu (2012), 3B lazer tarayıc1 ve robot kol kullanarak oluşturdukları robotik sistem ile iş parçasının yüzey modeli oluşturmuşlardır. İmalat sürecinde üretimi iyileştirmek amacıyla 6 eksenli endüstriyel robot kolun ucuna lazer sensör entegre ederek kalite kontrolünün iyileştirilmesi hedeflenmiştir (Al Khawli, Anwar, Gan \& Islam, 2021). Yapılan çalışmalar; lazer sensörlerin, endüstriyel robot kollar ile entegre çalışabildiği sistemler sayesinde, imalat sonrası süreçte ürün kontrolünün hassas bir şekilde yapılabilirliğini göstermektedir. Bu doğrultuda yapılan çalışmada, serbest yüzeye sahip metal parçaların imalatı sırasında gerçekleşen hata miktarlarının, robot kol üzerinde bulunan lazer sensör ile noktasal tespiti hedeflenmiştir.

\section{Materyal ve Metot}

Çalışmada; endüstride kullanılan ölçüm yöntemlerine alternatif oluşturmak amaciyla, serbest form yüzeye sahip titanyum numunenin imalatı sonrasında gerçekleşen hata miktarlarının tespiti yapılmıştır. Hata miktarları için noktasal lazer sensör ile ölçümler yapılmış ve hesaplamalarla hata miktarları tespit edilmiştir. Numunenin üretimi sonrasında oluşan toleransın yüksek hassasiyet ile tespiti için lazer sensör; 6 eksen ve $10 \mu \mathrm{m}$ hassasiyete sahip ABB IRB 120 model robot kolun üzerine bir aparat kullanılarak entegre edilmiştir. Oluşan bu sistem ile lazer sensöre 6 eksende hareket kabiliyeti kazandırılmıştır. Şekil 1'de lazer sensörün robot kola entegre edilmesiyle oluşturulan robotik sistem düzeneği görülmektedir.

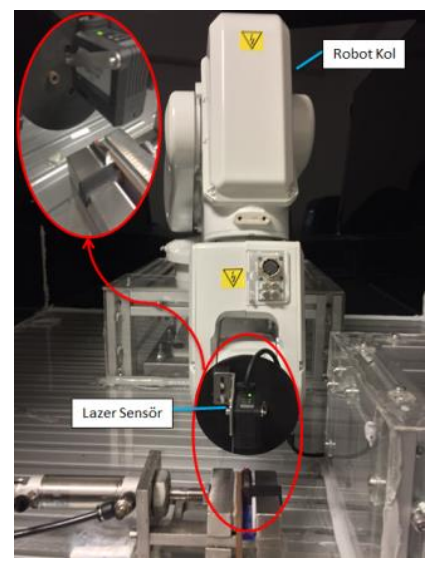

Şekil 1. Robotik sistem düzeneği

Tablo 1' de çalışmada kullanılan lazer sensör ve robot kolun teknik özellikleri verilmiştir.

Tablo 1. Lazer sensör ve robot kolun özellikleri

\begin{tabular}{|c|c|}
\hline Lazer Sensör & Özellik \\
\hline Model & Keyence IL-030 \\
\hline \multirow[t]{3}{*}{ Türü } & Yarı iletken kırmızı \\
\hline & lazer \\
\hline & $\begin{array}{l}\text { Dalga boyu: } 655 \mathrm{~nm} \\
\text { (görünür 1ş1k) }\end{array}$ \\
\hline \multirow[t]{3}{*}{ Sinıfi } & Class 1 (FDA $(\mathrm{CDRH})$ \\
\hline & Part1040.10) \\
\hline & Class 1 (IEC 60825-1) \\
\hline Referans mesafesi & $20 \mathrm{~mm}$ \\
\hline Ölçüm aralığı & $20-45 \mathrm{~mm}$ \\
\hline Spot çapı (standart mesafede) & Yaklaşık 200x750 $\mu \mathrm{m}$ \\
\hline Doğrusallık & $\begin{array}{l}\% 0,1(25-30 \mathrm{~mm} \\
\text { aralığında })\end{array}$ \\
\hline Yinelenebilirlik & $1 \mu \mathrm{m}^{-4}$ \\
\hline Örnekleme oranı & $0.33 / 1 / 2 / 5 \mathrm{~ms}$ \\
\hline A ğırlık & Yaklaşık 60 gram \\
\hline Robot kol & Özellik \\
\hline Model & ABB IRB 120 \\
\hline Eksen sayısı & 6 \\
\hline Koruma & IP 30 \\
\hline Kontrolcü & $\begin{array}{c}\text { IRC5 compact / IRC5 } \\
\text { single cabinet }\end{array}$ \\
\hline Hızlanma süresi 0-1 m/s & $0.07 \mathrm{~s}$ \\
\hline Pozisyon hassasiyeti & $0.01 \mathrm{~mm}$ \\
\hline
\end{tabular}

1127 
Robot kol üzerine entegre edilmiş bir lazer ölçüm sistemi kullanılarak, nesnelerin konumunun 3B koordinat sisteminde yüksek oranda doğru ölçülebilmesi için çeşitli bileşenlerin önceden kalibre edilmesi gerekmektedir (Zhuang, Roth \& Sudhakar, 1994; Zhuang, Wang \& Roth, 1998). Bu amaçla numune üzerinde bir orijin noktası belirlenmiştir. Orijin noktası referans alınarak lazer sensör konumlandırılmıştır. Lazer sensörün orijin noktasına olan uzaklığı $(\mathrm{K})$, lazerin teknik özelliğinden dolayı ölçüme başladığı mesafe, lazer sensörün belirlenen noktalardan ölçtüğü değer $(\Delta s)$ ve yüzey geometrisini belirleyen nokta yüksekliği $(\Delta Y)$ Şekil 2'de bulunan şematikte görülmektedir.

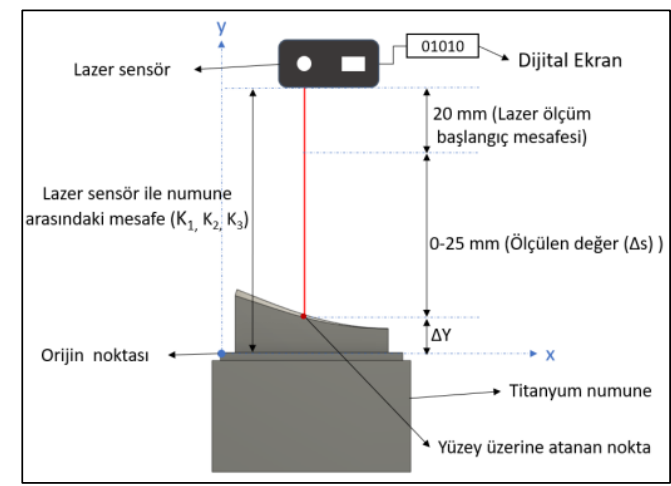

Şekil 2. Numunenin lazer sensör ile ölçülmesinin şematik gösterimi

Şekil 2'de verilen bu mesafeler kullanılarak, Eşitlik 1'de yüzey geometrisini belirleyen nokta yüksekliği $(\Delta \mathrm{Y})$ hesaplanmıştır. Bu işlem yüzey üzerinde belirlenen her nokta için gerçekleştirilmiştir.

$$
\Delta \mathrm{Y}=\mathrm{K}-(20+\Delta \mathrm{s})
$$

Kompresör kanatçık yüzeylerinin karmaşık geometriye sahip olması ve yüksek hassasiyetli üretime ihtiyaç duymasından dolayı deneylerde blisk geometrisi kullanılmıştır. Numunenin yüzeyi düzensiz temelli eğri yüzey yöntemi kullanılarak tasarlanmıştır. Numunenin serbest forma sahip yüzeyinin 3B koordinat tespitinin yapılabilmesi için SolidWorks ortamında yüzeye belirli mesafelerde noktalar tanımlanmıştır. Her noktanın koordinatı numunenin orijin noktasına göre belirlenmiştir. Numunenin pnömatik mengenedeki konumu Flexpendant kullanılarak belirlenmiştir. Numunenin CAD modeli RobotStudio ${ }^{\circledR}$ ortamına aktarılmıştır. RobotStudio ortamında robot kolun, numunenin ve lazer sensörün konumlandırmaları yapılmıştır. SolidWorks ortamında belirlenen noktalar kullanılarak hedefler oluşturulmuştur. Hedefler kullanılarak robot kolun hareketi için 3 farklı çizgisel yörüngeler (Yörünge I, Yörünge II, Yörünge III) oluşturulmuştur. RobotStudio ortamında oluşturulan çizgisel yörüngeler offset özelliği kullanılarak 3 farklı mesafe (42 mm, $44.5 \mathrm{~mm}, 47 \mathrm{~mm}$ ) için tasarlanmıştır. Robot kolun hareket hızı, tüm deneyler için $5 \mathrm{~m} / \mathrm{s}$ olarak belirlenmiştir. Noktalar arasındaki mesafe $1 \mathrm{~mm}$ altında olduğu için RobotStudio Zone özelliği, tüm deneyler için $\mathrm{Z} 0$ olarak belirlenmiştir.

Deney şartları RobotStudio ortamında simülasyon edilmiştir. Çizgisel yörüngelere ait RAPID kodları kontrol edilmiştir. RAPID kodları, IRC 5 robot kontrolcüsü ile robot kola aktarılarak lazer sensörün, çizgisel yörüngeleri takip edebilmesi sağlanmıştır.

Deneylerde kullanılan noktalar için, $i$ ekseni 13 nokta ile sabit tutulmuştur. $j$ eksenine ise 3, 4 ve 5 olarak değişken değerler tanımlanmıştır. Böylece 39, 52 ve 65 adet olmak üzere 3 farklı nokta sayısı elde edilmiştir. 3 farklı sayıda atanan noktalar ile robot kolun hareketi için 3 farklı çizgisel yörünge oluşturulmuştur.

6 eksenli robot kolun her ekseninde bulunan uzuvların uzunluğu, hareket sırasında yaptığı açı, güç tüketimi, sıcaklık (Paryanto vd., 2014) ve açısal hareketinin birbirinden farklı olmasından dolayı hareket hassasiyetinde farklılıklar görülebilmektedir. Bu nedenle robot kolun izleyeceği hareket için 3 farklı çizgisel yörünge oluşturulmuştur. Şekil 3 'te oluşturulan yörüngelerin geometrileri görülmektedir.

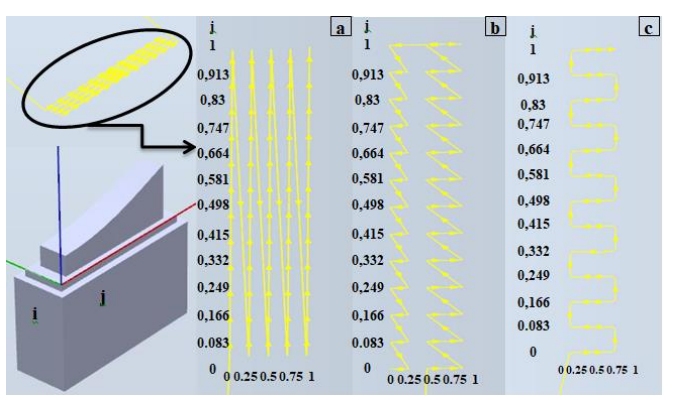

Şekil 3. Yörünge geometrileri a) I. yörünge b) II. yörünge c) III. Yörünge

Bu çalışmada; lazer sensörün ölçüm mesafesi $\left(\mathrm{K}_{1,2,3}\right)$, robot kolun izlediği çizgisel yörünge ve numune üzerine lazer sensör ile ölçüm almak için atanan nokta sayısı olmak üzere 3 adet farklı değişken kullanılmıştır. Her deney değişkeni için ise 3 'er farklı değişken kullanılmış olup toplamda 27 adet deney yapılmıştır. Deney şartları Tablo 2'de verilmiştir.

Tablo 2. Deney şartları

\begin{tabular}{|c|c|c|c|}
\hline Deney No & $\begin{array}{l}\text { Nokta } \\
\text { Sayısı } \\
\end{array}$ & $\begin{array}{l}\text { Yörünge } \\
\text { Şekli }\end{array}$ & $\begin{array}{l}\text { Mesafe } \\
(\mathrm{mm})\end{array}$ \\
\hline 1 & 39 & I & 42 \\
\hline 2 & 39 & $\mathrm{I}$ & 44,5 \\
\hline 3 & 39 & I & 47 \\
\hline 4 & 52 & $\mathrm{I}$ & 42 \\
\hline 5 & 52 & I & 44,5 \\
\hline 6 & 52 & I & 47 \\
\hline 7 & 65 & I & 42 \\
\hline 8 & 65 & $\mathrm{I}$ & 44,5 \\
\hline 9 & 65 & I & 47 \\
\hline 10 & 39 & II & 42 \\
\hline 11 & 39 & II & 44,5 \\
\hline 12 & 39 & II & 47 \\
\hline 13 & 52 & II & 42 \\
\hline 14 & 52 & II & 44,5 \\
\hline 15 & 52 & II & 47 \\
\hline 16 & 65 & II & 42 \\
\hline 17 & 65 & II & 44,5 \\
\hline 18 & 65 & II & 47 \\
\hline 19 & 39 & III & 42 \\
\hline 20 & 39 & III & 44,5 \\
\hline 21 & 39 & III & 47 \\
\hline 22 & 52 & III & 42 \\
\hline 23 & 52 & III & 44,5 \\
\hline 24 & 52 & III & 47 \\
\hline 25 & 65 & III & 42 \\
\hline 26 & 65 & III & 44,5 \\
\hline 27 & 65 & III & 47 \\
\hline
\end{tabular}


Deney şartlarının numune değerleri ile kıyaslanabilmesi için numunenin boyutsal ölçüm değerleri LK-Integra model CMM ile ölçülmüştür. Boyutsal ölçüm değerleri için Camio 8.4 yazılımı kullanılmıştır. CMM cihazına ait özellikler Tablo 3'te gösterilmiştir.

Tablo 3. CMM cihazı özellikleri

\begin{tabular}{cc}
\hline LK-Integra & Özellikler \\
\hline Hacimsel Doğruluk & $4,5 \mu \mathrm{m}+\mathrm{L} / 200$ \\
Tekrarlanabilirlik & $4,5 \mu \mathrm{m}$ \\
Hız & $533 \mu \mathrm{mm} / \mathrm{s}$ \\
İvme & $631 \mathrm{~mm} / \mathrm{s}^{2}$ \\
\hline
\end{tabular}

Ölçümlere hata miktarların ortalaması hesaplanmıştır. Hesaplamada Eşitlik (2) kullanılmıştır.

$$
\text { Ortalama hata miktarı }=\frac{|\mathrm{x} 1+\mathrm{x} 2+\cdots+\mathrm{xn}|}{n}
$$

\section{Araştırma Sonuçları ve Tartışma}
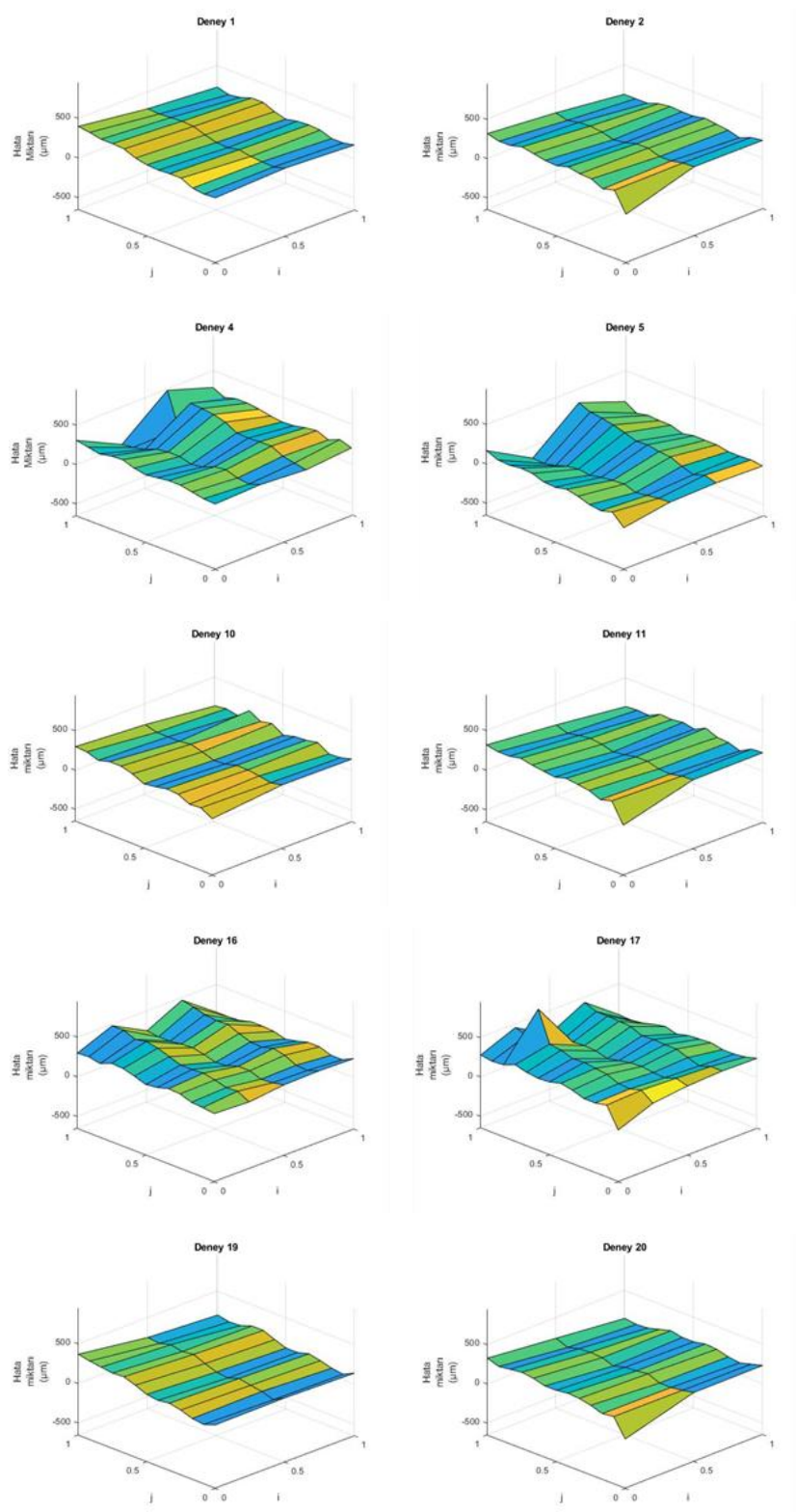

CMM cihazında numune yüzeyinde noktalar belirlenip ölçümler temasa dayalı ölçüm uçları aracılığıyla gerçekleştirilmiştir. Yapılan ölçümler sonucunda 5-106 $\mu \mathrm{m}$ hata miktarları elde edilmiştir. Hata miktarları; 0-20 $\mu \mathrm{m}, 20-50 \mu \mathrm{m}$, 50-80 ve 80-106 $\mu \mathrm{m}$ arasında gruplandırılmıştır. Hata miktarlarının yoğunlukları en azdan en fazlaya doğru; 80-106 $\mu \mathrm{m}$, 0-20 $\mu \mathrm{m}, 50-80 \mu \mathrm{m}, 20-50 \mu \mathrm{m}$ olarak siralanmıştır. Hata miktarlarının ortalaması alındığı zaman ise $55 \mu \mathrm{m}$ değeri elde edilmiştir.

Numunenin CAD modelinden elde edilen noktaların serbest forma sahip yüzeye mesafesi ile her nokta için belirlenmiştir. Lazer sensör ölçümle elde edilen sonuçların CAD modelden elde edilen sonuçlara göre farkı $\mu \mathrm{m}$ olarak hesaplanmıştır. Sonuçlar MATLAB ortamında 3 boyutlu grafiklere dönüştürülmüştür. Elde edilen sonuçların $\mathrm{CAD}$ modele benzerlik oranları yüzde olarak hesaplanmıştır.

Tablo 2'de gösterilen deney şartına ait hata miktarlarının $(\mu \mathrm{m})$ grafikleri Şekil 4'te gösterilmiştir. Grafiklerdeki Z ekseni için sabit değer minimum $-650 \mu \mathrm{m}$, maksimum $950 \mu \mathrm{m}$; $X$ ve $Y$ eksenleri için 0-1 arasında sabit tutulmuştur. Grafiklerde renk skalası kullanılmıştır.
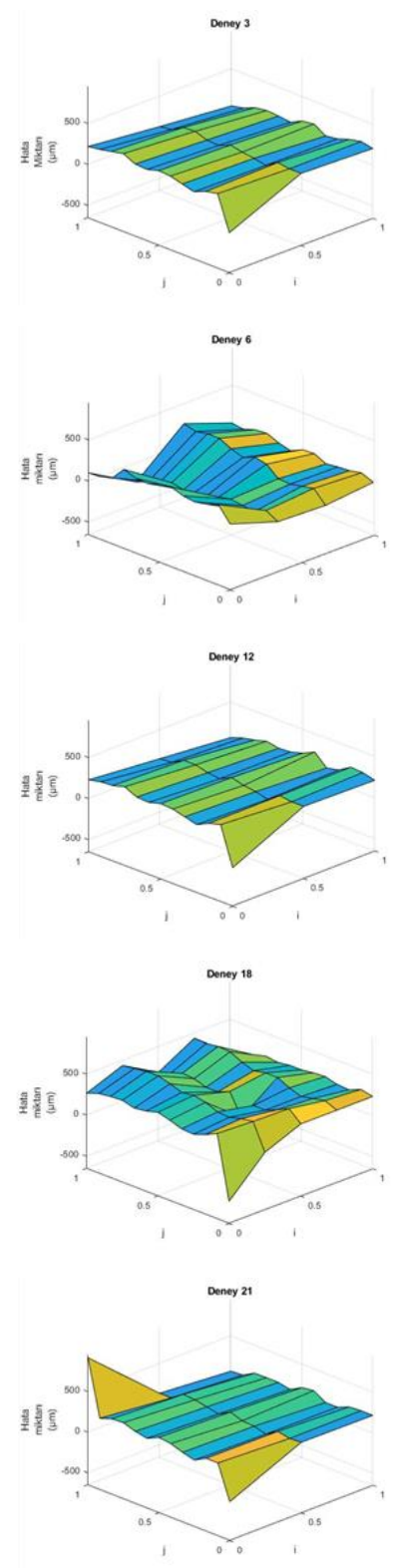

Şekil 4. Deney şartlarına göre hata miktarı grafikleri 
Grafiklere göre nokta sayısı arttıkça grafikte tahmin edilebilirliğin yani homojen dağılımın azaldığı görülmektedir. Nokta sayısının en az olduğu Deney 1-2-3-10-11-12-19-20-21 grafiklerinde homojen dağılım gözlemlenmiştir. Diğer deney şartlarının homojen bir dağılım göstermediği belirlenmiştir. Diğer deneyler nokta sayılarına göre kıyaslandığı zaman 52 noktaya ait Deney 4-5-6-13-14-15-22-23-24 grafiklerinin, 65 noktaya ait Deney 7-8-9-16-17-18-25-26-27 grafiklerine göre daha homojen bir dağılım gösterdiği gözlemlenmiştir. Elde edilen sonuca göre grafiklerdeki homojen dağılımın nokta sayısı arttıkça azaldığı tespit edilmiştir.

Ortalama hata miktarları değerlendirildiğinde standart sapma değeri diğer deney şartlarına göre düşük olan deney 1-2-3-10-1119-20 olduğu belirlenmiştir. $\mathrm{Bu}$ deney şartlarının 39 nokta sayısına sahip olduğu tespit edilmiştir. Buna göre ortalama hata miktarına göre en azdan en fazlaya doğru yörüngeler karşılaştırıldığında; Yörünge I, Yörünge III, Yörünge II olduğu belirlenmiştir. Yörüngeler standart sapma değerine göre karşılaştırıldığında; Yörünge I, Yörünge II, Yörünge III olarak sıralanmıştır. Yörünge I'in ortalama hata miktarı ve standart sapma değerleri için en iyi sonuçları verdiği gözlemlenmiştir. Yörünge II, Yörünge III'e göre daha düşük bir standart sapma değerine sahip olduğu için grafiklerde daha homojen bir dağılım göstermiştir. Buradan elde edilen sonuçlara göre, standart sapma değerinin homojen dağılımla ters orantıda bulunduğu belirlenmiştir.

39 nokta sayısında farklı mesafeler değerlendirildiğinde; Yörünge I'de 39 nokta için mesafe arttıkça ortalama hata miktarının azaldığı gözlemlenmiştir. Aynı değişkenlere göre Yörünge II ve III için mesafenin arttıkça ortalama hata miktarlarında artış gözlemlenmiştir. 52 nokta için bütün yörüngeler benzer davranış göstermiştir. 65 nokta için Yörünge I'de mesafe arttıkça ortalama hata miktarında azalma olduğu belirlenmiştir. Aynı değişkenlerde Yörünge I ve II için mesafenin artması sonucu ortalama hata miktarı da artmıştır. Nokta sayısının ve mesafenin arttırılması tüm deney şartlarında Yörünge II için CMM sonuçlarına en uzak değerleri vermiştir.

3 farklı mesafede ortalama hata miktarının değerlendirilmesi sonucunda mesafe arttıkça ortalama hata miktarının arttığ sonucuna ulaşılmıștır.

Çizgisel yörüngelerde oluşan farkları daha iyi inceleyebilmek için robot kolun her hareketi için 6 eksendeki açısal değişimleri hesaplanmıştır. 65 nokta için 3 farklı yörüngede ve $42 \mathrm{~mm}$ mesafede robot kolun 6 eksende açısal olarak yaptığı değişimler Şekil 5 'te gösterilmiştir.
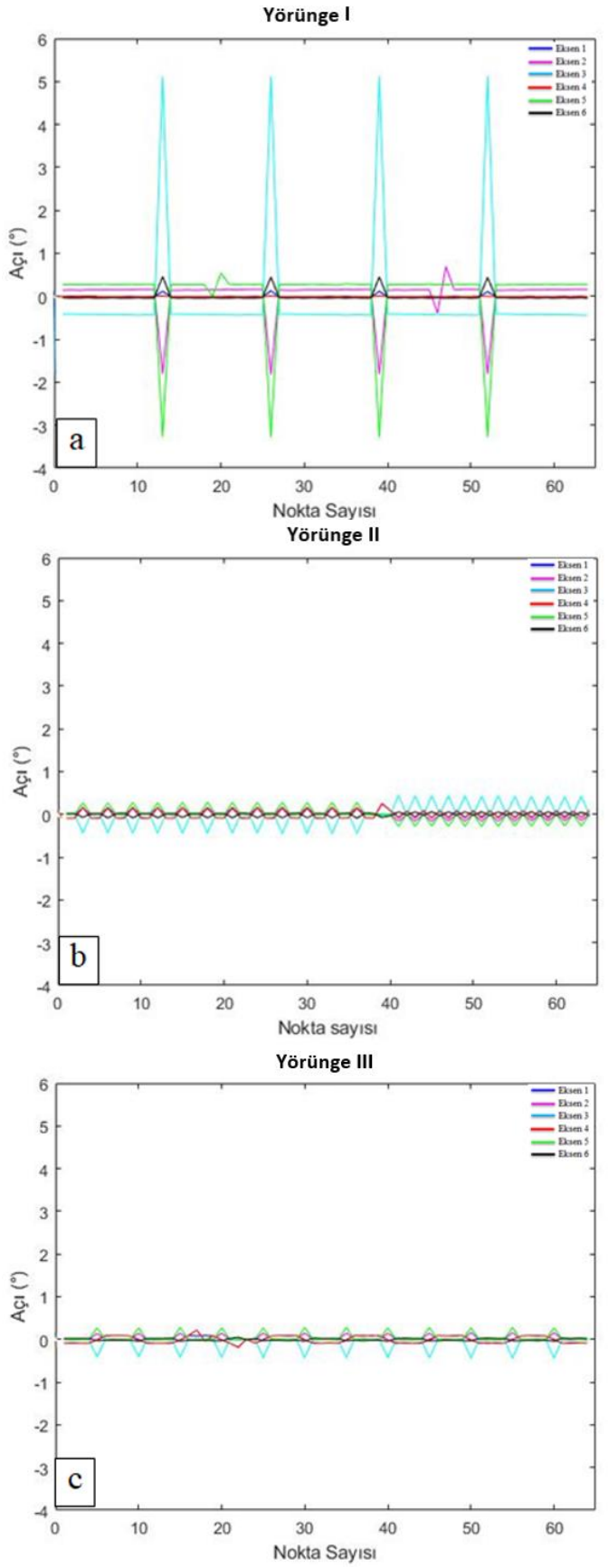

Şekil 5. Robot kol eksen hareketleri a) I. Yörünge b) II. Yörünge c) III. Yörünge

65 noktaya göre 3 yörünge için eksen hareketleri incelendiğinde açı hareketlerinin $-4^{\circ}$ ile $6^{\circ}$ arasında değişim göstermiştir. Numunenin $i$ ve $j$ eksenlerinde robot kol hareket ettiği belirlenmiştir. $i$ ekseninde 2,3 ve 5 numaralı robot eksenleri; $j$ ekseninde 1,4 ve 6 numaralı robot eksenleri kullandı̆̆

Yörünge I'in eksen hareketleri incelendiğinde; her 13 noktada sadece $1 \mathrm{kez}$ açısal değişim olduğu gözlemlenmiştir. $i$ ekseninde hareketin olduğu 13.-26.-39.-42. noktalarında açısal değişimin olduğu belirlenmiştir. Diğer 61 nokta için açısal değişiminin 0'a yakın olduğu gözlemlenmiştir. Ortalama hata miktarını ve standart sapma değerinin sonuçlarıyla birlikte değerlendirildiğinde; eksenlerdeki açısal değişimin en aza indirgenmesi homojenliği ve hata miktarını azalttığı belirlenmiştir. 
Yörünge II'deki eksen hareketleri incelendiğinde; $i$ ve $j$ eksenlerinde açıların $24 \mathrm{kez}$ değiştiği belirlenmiştir. Açısal değişimler $-0,5^{\circ}$ ile $0,5^{\circ}$ arasında hesaplanmıştır. $i$ ve $j$ eksenlerindeki açısal değişimin sıklığının sonucu olarak hata miktarının Yörünge I'den fazla olduğu belirlenmiştir.

Yörünge III'ün $j$ ekseninde 13 defa açısal değişim olduğu gözlemlenmiştir.

Hata miktarları incelendiğinde eksen hareketlerindeki açısal değişimlerin en az olduğu Yörünge I'in en düşük, en fazla olduğu Yörünge II'nin ise en yüksek oranda hata miktarına sahip olduğu belirlenmiştir. Ayrıca Yörünge I ve Yörünge III'de değişimler sırasında tek eksende; Yörünge II'de ise 2 eksende hareketin olduğu tespit edilmiştir. Hareket esnasında kullanılan eksen sayısının azaltılması ile homojen dağılıma arasında doğru orantı olduğu bulunmuştur.

3 yörünge için $44,5 \mathrm{~mm}$ ve $47 \mathrm{~mm}$ mesafelerinde yapılan eksen hareketleri incelendiğinde; açı değerlerinin farklı fakat açısal değişim değerlerinin aynı olduğu tespit edilmiştir. 3 farklı mesafe için yapılan incelemede mesafe değişimlerinin açısal değişimi etkilemediği belirlenmiştir. Bu sonuç Şekil 4'teki grafiklerle kıyaslandığında; aynı yörünge ve nokta sayısı için farklı mesafelerde yapılan deneylerde mesafenin hata miktarlarındaki homojen dağılıma etkisinin en az olduğu belirlenmiştir. Mesafenin homojenlik veya standart sapma üzerine etkisi nokta sayısı ve yörünge şekline göre en azdır.

CMM sonuçları ile 27 deney şartı karşılaştırıldığında; deney şartı 5-6-7-8-9-14-15-23-25'e ait hata miktarlarının 5-106 $\mu \mathrm{m}$ arasında olduğu belirlenmiştir. Diğer deney şartları için yapılan ortalama hata miktarı hesaplamalarında belirlenen CMM sonuç aralığının dışında olduğu tespit edilmiştir. Diğer deney şartlarının CMM sonuçlarına göre hata miktarı yaklaşık olarak 136,77 $\mu \mathrm{m}$ fazla olduğu belirlenmiştir. $136,77 \mu \mathrm{m}$ değer; hata oranı cinsinden ortalama \%0,757 olarak hesaplanmıştır. Hata miktarı olarak CMM sonuçlarına göre; 9 deney şartı için benzer sonuç, diğer 14 deney için \%0,757 ortalama hata miktarında artış olduğu belirlenmiştir.

$\mathrm{Bu}$ sonuçlar tüm deney şartları ile değerlendirildiğinde; Yörünge I'in ortalama hata miktarı olarak CMM sonuçlarına en yakın olduğu belirlenmiştir. En iyi sonuç ise deney şartı 8'de elde edilmiştir.

Nokta sayısı olarak CMM sonuçları incelendiğinde, en iyi sonuç 52 noktada elde edilmiştir. CMM sonuçları mesafe değerlerine göre kıyaslandığında ise her mesafenin hata miktarı olarak birbirine yakın değerler verdiği sonucuna ulaşılmıştır. Hata miktarlarında homojen dağılımın düşük olduğu durumların sebepleri incelendiğinde; sirasıyla nokta sayısı, eksenlerdeki açısal değişimler, yörünge farklılıkları ve mesafe değerleri olduğu belirlenmiştir.

\section{Sonuç}

$\mathrm{Bu}$ çalışmada; serbest form yüzeye sahip bir titanyum numunenin imalat sonrası yüzey ölçüm değerlerinin, robot kola entegre edilmiş lazer sensörle ölçülmesi sağlanmıştır. Ölçülen değerlerin CMM cihazından alınan boyutsal ölçüm değerleri ile karşılaştırması yapılmıştır. Yapılan ölçümlerde hata miktarları, ortalama hata miktarına ait standart sapma değerleri ve robot kolun eksenlerindeki açısal değişimleri değerlendirilmiştir. 27 farklı deneyde toplam 1404 nokta üzerinden elde edilen sonuçlara göre; nokta sayısının hata miktarındaki homojen dağılıma en fazla etkisinin olduğu belirlenmiştir. Numune yüzeyinde oluşturulan çizgisel yörüngelerin ise lazer sensör mesafesine kıyasla, hata miktarlarındaki homojen dağılım üzerinde daha fazla etkisi olduğu belirlenmiştir.

Robot kolun hareketleri sırasında açısal değişimleri incelendiğinde; açısal değerlerdeki değişimin artışı hata miktarındaki homojenliğe olumlu etkilediği belirlenmiştir. Açısal değişimin miktarında artış olduğu zaman hata miktarlarındaki homojen dağılımı olumsuz etkilediği belirlenmiştir.

Mesafeye göre değerlendirildiğinde, ortalama hata miktarının mesafe arttıkça arttığı belirlenmiştir. Nokta sayısının ve mesafenin arttırılması tüm deney şartlarında Yörünge II için CMM sonuçlarına en uzak değerleri vermiştir.

Ortalama hata miktarı değerleri göz önüne alındığında, artan nokta sayısı ile doğrudan ilişki içinde olduğu belirlenmiştir. Standart sapma değerlerinin en az olduğu durumlarda, hata miktar değerlerinin en fazla homojen dağılım gösterdiği belirlenmiştir.

$\mathrm{Bu}$ çalışmada robot kola bağlı lazer sensörle yapılan ölçümlerin, serbest form yüzeye sahip metaller için CMM cihazları yerine kullanılabilirliğini gösterilmiştir. Lazer ölçüm sonuçları CMM değerlerini 9 deney şartında sağlamıştır. 18 deney şartında ise \%0,757 değerinde bir sapma ile CMM sonuçlarını sağlamıştır. Ortalama hata miktarlarına ve benzerlik oranlarına göre değerlendirildiğinde robot kola bağlı lazer sensörle yapılan ölçümlerin gelişime açık bir alan olduğu belirlenmiştir.

\section{Teşekkür}

Bu çalışma Türkiye Bilimsel ve Teknolojik Araştırma Kurumu (TÜBİTAK) tarafindan desteklenmektedir (Proje numaras1: 119R009).

\section{Kaynakça}

Germani, M., Mandorli, F., Mengoni, M., Raffaeli, R. (2010). CAD-based environment to bridge the gap between product design and tolerance control. J. Prec. Eng., 34, 7-15.

Huang, Y., Qian, X. (2007). A dynamic sensing-and-modeling approach to three-dimensional point-and-area-sensor integration. J. Manuf. Sci. Eng., 129, 623-635.

Hwang, C. Y., Tsai, C. Y., Chang, C. A. (2004). Efficient inspection planning for coordinate measuring machine. J. Adv. Manuf. Technol., 23, 732-742.

Kruth, J. P., Van Gestel, N., Bleys P., Welkenhuyzen, F. (2009). Uncertainty determination for CMMs by Monte Carlo simulation integrating feature form deviations. CIRP Ann. Manuf. Technol., 58, 463-466.

Li, Y., Gu, P. (2004). Free-form surface inspection techniques state of the art review. Computer-Aided Des., 36, 13961417.

Lee, G., Mou, J., Shen, Y. (1997). Sampling strategy design for dimensional measurement of geometric features using coordinate measuring machine. J. Mach. Tools Manuf., 37, 917-934.

Lee, K.H., Park, H. (2000). Automated inspection planning of free-form shape parts by laser scanning. J. Robot. Comput Integr. Manuf., 16, 201-210.

Martins, F., Garcia-Bermeio, F., Casanova, E., Gonzalez, J. (2005). Automaed 3D surface scanning based on CAD model, J. Mechatron., 15, 837-857. 
Weckenmann, A., Jiang, X., Sommer K.D., Neuschaefer-Rube, U. (2009) Multisensor data fusion in dimensional metrology. CIRP Ann. - Manuf. Technol., 58, 701-721.

Nashman, M., Yoshimi, B., Hong, H., Rippey, W. (1997). A unique sensor fusion system for coordinate measuring machine tasks. Proc. SPIE Intell. Syst. Adv. Manuf., 3209, 145-156.

Bradley, C., Chan, V. (2001) A complementary sensor approach to reverse engineering. J. Manuf. Sci. Eng., 123, 74-82.

Carbone, V., Carocci, M., Savio, E., Sansoni, G. (2001). Combination of a vision system and a coordinate measuring machine for the reverse engineering of freeform surfaces. J. Adv. Manuf. Technol, 17, 263-271.

Shen, T., Huang, J., Menq, C. (2001). Multiple sensor planning and information integration for automatic coordinate metrology. J. Comput. Inform. Sci. Eng., 1, 167-179.

Zhao, H., Kruth, J. P., Van Gestel, N., Boeckmans, B., Bleys, P. (2012). Automated dimensional inspection planning using the combination of laser scanner and tactile probe. Measurement, 45, 1057-1066.

Cheng, W. L., Menq, C. H. (1995). Integrated laser/CMM system for the dimensional inspection of objects made of soft material. The International Journal of Advanced Manufacturing Technology, 10, 36-45.

Morozov, M., Pierce, S. G., MacLeod, C. N., Mineo, C., Summan, C. (2018). Off-line scan path planning for robotic NDT. Measurement, 122, 284-290.

Heeshin, K. (2016). Study on Synchronization for Laser Scanner and Industrial Robot. Int. J. Sci. Eng. Appl. Sci. 2, 23953470 .

Hatwig, J., Reinhart G., Zaeh, M. F. (2010). Automated task planning for industrial robots and laser scanners forremote laser beam welding and cutting. Prod. Eng., 4, 327.

Idrobo-Pizo, G. A., Motta, J. M. S., Sampaio, R. C. (2019). A calibration method for a laser triangulation scanner mounted on a robot arm for surface mapping. Sensors, 19(8), 1783.

Niola, V., Rossi, C., Sergio, S., Salvatore, S. A. (2010). Method for the calibration of a 3-D laser scanner, Robot. Comput.Integr. Manuf., 27, 479-484.

Ren, Y., Yin, S., Zhu, J. (2012). Calibration technology in application of robot-laser scanning system. Opt. Eng., 51.

Li, J., Chen, M., Jin, X., Chen, Y., Dai, X., Ou, Z., Tang, Q. (2011). Calibration of a multiple axes 3-D laser scanning system consisting of robot, portable laser scanner and turntable. Opt. Int. J. Light Electron. Opt., 122, 324-329.

Tzafestas, S. G., Raptis, S., Pantazopoulos, J. A. (1996). VisionBased Path Planning Algorithm for a Robot-Mounted Welding Gun. Image Process. Commun, 2, 61-72.

Hatwig, J., Minnerup, P., Zaeh M. F., Reinhard, G. (2012). An Automated Path Planning System for a Robot with a Laser Scanner for Remote Laser Cutting and Welding. In Proceedings of the IEEE International Conference on Mechatronics and Automation, 5, 1323-1328.

Shirinzadeh, B., Teoh, P. L., Tian, Y., Dalvand, M. M., Zhong, Y., Liaw, H. C. (2010). Laser interferometry-based guidance methodology for high precisión positioning of mechanisms and robots. Robot, Comput.-Integr. Manuf., 26, 74-82.

Fu, S., Cheng, F., Tjahjowidodo, T., Zhou, Y., Butler, D. A. (2018). Non-Contact Measuring System for In-Situ Surface Characterization Based on Laser Confocal Microscopy. Sensors, 18, 2657.

Shen, C., Zhu, S. (2012). A robotic system for surface measurement via 3D laser scanner. Reconstruction, 1: 2.
Deng, W., Shark, L. K., Matuszewski, B. J., Smith, J. P., Cavaccini, G. (2004). CAD model-based inspection and visualisation for $3 \mathrm{D}$ non-destructive testing of complex aerostructures. Insight-Non-Destructive Testing and Condition Monitoring, 46, 157-161.

Al Khawli, T., Anwar, M., Gan, D., Islam, S. (2021). Integrating laser profile sensor to an industrial robotic arm for improving quality inspection in manufacturing processes. Proceedings of the Institution of Mechanical Engineers, Part C: Journal of Mechanical Engineering Science, 235, 4-17.

Zhuang, H., Roth, Z. S., Sudhakar, R. (1994). Simultaneous robot/world and tool/flange calibration by solving homogeneous transformation equations of the form $\mathrm{AX}=$ YB. IEEE Trans. Robot. Autom., 10, 549-554.

Zhuang, H., Wang, K., Roth, Z. S. (1998). Simultaneous calibration of a robot and a hand-mounted camera. IEEE Trans. Robot. Autom., 11, 649-660.

Paryanto, Brossog, M., Kohl, J., Merhof, J., Spreng, S., Franke, J. (2014). Energy consumption and dynamic behavior analysis of a six-axis industrial robot in an assembly system. Procedia CIRP 23, $131-136$. 